\title{
Research Article \\ SCREENING OF POTENTIAL MICROALGAE SPECIES FROM DIFFERENT NATURAL ENVIRONMENT FOR BIODIESEL PRODUCTION
}

\section{MACHEGOWDA HARINIKUMAR KODIHALLI*, TAMULPAUDI SRIAPPAREDDY, BASAVEGOWDA MANOJ KUMAR HANIYAMBADI AND MUNISAMY PURUSHOTHAMAN YELAGIRI}

Department of Plant Biotechnology, University of Agricultural Sciences, GKVK Campus, Bangalore, 560065, Karnataka, India

*Corresponding Author: Email-manojmandya.17@gmail.com

Received: February 15, 2018; Revised: March 12, 2018; Accepted: March 13, 2018; Published: March 30, 2018

\begin{abstract}
Microalgal samples were collected from different regions of India. The samples thus obtained were serially diluted, colonies were further purified and identified as Desmodesmus abundans, Scendesmus pectinatus, Tetranephris brasiliensis, Desmodesmus armatus, Scendesmus costato-granulatus, Neocystis brevis, Chlorella sorokiniana, Scendesmus acutus, Pseudomuriella species and Chlorella minutissima by 18s rRNA sequencing. The effect of growth conditions was studied under different media such as Bold Basal Media (BBM), Blue Green 11 media (BG11) and Tris-Acetate Phosphate media (TAP). The highest growth rate was occurred in Desmodesmus abundans on $19^{\text {th }}$ day in TAP media whereas the lowest growth rate was occurred in Tetranephris brasiliensis in BBM media. Under similar environmental conditions average specific wet and dry biomass were found maximum in Chlorella minutissima, Desmodesmus abundans and Scendesmus costatogranulatus in TAP media when compared to BBM and BG11. The highest amount of lipid was obtained in Desmodesmus armatus (43.7\%) grown in TAP media. Nile red staining and thin layer chromatography confirms the accumulation of total lipids. The reaction condition with that of $n$-hexane to methanol ratio $1: 2$, solvent dosage $5.0 \mathrm{ml}$, reaction temperature $90^{\circ} \mathrm{C}$, reaction time $2.0 \mathrm{~h}$ and catalyst volume $0.5 \mathrm{ml}$ of the direct transesterification can reach the conversion yield of $90.23 \%, 89.25 \%$ and $86.65 \%$ found in Desmodesmus abundans, Desmodesmus armatus and Scendesmus costato-granulatus respectively. There is a prospective in algal biotechnology by exploitation of different media composition for the growth formulation in microalgae species which is inexpensive for biomass cultivation in large scale production of lipids that can be harnessed for biodiesel production.
\end{abstract}

Keywords- Microalgae, Biomass, Lipids, Transesterification and Biodiesel

Citation: Machegowda Harinikumar Kodihalli, et al., (2018) Screening of Potential Microalgae Species from Different Natural Environment for Biodiesel Production. International Journal of Microbiology Research, ISSN: 0975-5276 \& E-ISSN: 0975-9174, Volume 10, Issue 3, pp.-1052-1057. DOl: http://dx.doi.org/10.9735/0975-5276.10.3.1052-1057

Copyright: Copyright@2018 Machegowda Harinikumar Kodihalli, et al., This is an open-access article distributed under the terms of the Creative Commons Attribution License, which permits unrestricted use, distribution and reproduction in any medium, provided the original author and source are credited.

Academic Editor / Reviewer: B. L. Raghunandan

\section{Introduction}

A constant rising worldwide demand of motor and power generation fuels, together with environmental concerns in terms of Green House Gases (GHG), has motivated the scientists and technologists to think about various alternate sources of energy. In recent years, a lot of thrust has been put on the search for the potential biomass feed stocks from different sources, which can be converted to liquid as well as gas fuels for energy generation [1]. Various biomasses have been identified as alternate source of energy fuels likely energy crops (e.g. edible as well as non-edible oilseeds and various aquatic plants identified as bio-oil sources) and bio-wastes (e.g. food wastes, municipal wastes, agricultural wastes and etc). Since vegetable oils may also be used for human consumption, it can lead to an increase in price of food grade oils, causing the cost of biodiesel to increase and preventing its usage, even if it has advantages comparing with diesel fuel [2]. Compared with oil crops, micro algae a vast group of photosynthetic organisms have higher photosynthetic efficiency, faster growth, synthesize and accumulate larger quantities of lipids $[3,4,5,6]$ to be most promising renewable biofuel producer that has the potential to completely displace fossil fuels without affecting supply of foods and other crop products. The oil yield from some microalgae is reported to exceed $70-80 \%$ (on dry weight basis) compared to $40 \%$ $50 \%$ from edible/non-edible oil seeds. Microalgae are tiny autotrophs that are capable of growing in extreme conditions and produce substantial amount of lipids that can easily be converted into the biofuels by bio-thermochemical methods.
Particularly, the neutral lipids-triacylglycerides (TAGs) which serve as energy storage for microalgae are converted into biodiesel through transesterification process $[7,8]$. Several advantages of algal biofuel have been identified by researchers. As per estimates, 20,000-80,000 L algae oil can be produced per acre which is 30 times higher than oil crops such as palm oil, sunflower oil and castor oil [6] and the microalgae are responsible for the global carbon fixation (more than $40 \%$ ) through the efficient utilization of carbon dioxide [9]. The microalgal compounds including triglycerides, antioxidants, pigments, betacarotene, polysaccharides, fatty acids and vitamins are widely used in different industrial sectors (e.g., biofuels, functional foods, nutraceuticals, pharmaceuticals, cosmetics and aquaculture) as bulk commodities [10]. However, commercialization of microalgae-based processes is bound to certain limitations [11]. Some article revealed that there are number of challenges in the economic cultivation of algae to enhance the oil extraction and fuel process, so that it can compensate petroleum and consequently mitigate $\mathrm{CO}_{2}$ release [12]. Other major challenges include strain isolation, selection of resources (i.e., nutrient and water) harvesting, fuel extraction, refining, utilization of residual algal biomass production, co-product development and management.

Hence the present study was focused on isolation of native microalgal species from a range of regions from southern part of India (Nilgiris, Dharmasthala and Goa) to evaluate their potential of growth condition with different commercial chemical media (Bold Basal Media, Blue Green 11 Medium and Tris-Acetate 
Phosphate media) for the production of lipids, with the ultimate goal of mass cultivation for biodiesel feedstock in the future.

\section{Material and Methods \\ Sample Collection and Isolation}

The samples containing microalgae were collected from different regions of southern India such as Nilgiris, Dharmasthala and Goa into sterile clean containers and shifted to laboratory conditions. Samples collected were serially diluted upto $10^{-6}$ and $1 \mathrm{ml}$ of each sample was transferred to a petri plates containing bold basal medium and incubated at $25 \pm 2^{\circ} \mathrm{C}$ under illumination chamber for 15 days. To attain the pure colonies inoculation procedure was repeated twice to make sure free from bacteria and fungi contamination. Slides of all the 10 pure cultures of the microalgal strains were observed in 40X Labomed CXR2 Wide Field Microscope.

\section{Species identification at molecular level}

Genomic DNA was extracted using a Amnion Algal gDNA isolation protocol. The purified genomic DNA was used as a template for amplification of partial $18 \mathrm{~S}$ rDNA using microalgal highly-specific primers

(18S F-5' GCATGGCCTATCTTGTTGGTCTGT - 3')

(18S R - 5' GCAGAATCAACCTGACAAGGCAAC-3')

PCR amplification have been performed in a final volume of $50 \mu \mathrm{l}$ containing $1 \mu \mathrm{l}$ DNA template, $2 \mu$ of $10 \mathrm{mM}$ dNTP, $5 \mu$ of $10 x$ PCR buffer with $2 \mathrm{mM} \mathrm{Mgcl} 2,2 \mu \mathrm{l}$ of each primer and $1 \mu \mathrm{l}$ of Taq Polymerase.

The cycling program have been carried out with the following conditions: $95^{\circ} \mathrm{C}$ $20 \mathrm{sec}$ for denaturation, $53^{\circ} \mathrm{C}-30 \mathrm{sec}$ for annealing, $72^{\circ} \mathrm{C}-45 \mathrm{sec}$ for extension followed by the final extension $72^{\circ} \mathrm{C}-5 \mathrm{~min}, 35$ cycles. The amplified PCR product is sequenced and the taxonomic identity of the microalgae was verified using BLAST analysis.

\section{Growth analysis}

All the isolated cultures were inoculated in $100 \mathrm{~mL}$ conical flasks containing different autoclaved media (BBM, BG-11and TAP). The chemical composition of the BBM, BG-11 and TAP are mentioned in [Table-1]. After inoculation the flasks were incubated at the temperature at $25 \pm 2^{\circ} \mathrm{C}, 16 / 8 \mathrm{~h}$ light: dark photoperiod under fluorescent white light for about 30 days. The observations of growth rate were measured on every alternative days at $600 \mathrm{~nm}$.

\begin{tabular}{|c|c|c|c|}
\hline \multicolumn{4}{|c|}{ Table-1 Chemical composition of different media } \\
\hline \multirow{2}{*}{ Chemical composition } & \multicolumn{3}{|c|}{ Concentration $\mathrm{mgL}^{-1}$} \\
\hline & BBM & BG11 & TAP \\
\hline Sodium Nitrate $\left(\mathrm{NaNO}_{3}\right)$ & 250 & 1500 & - \\
\hline Monopotassium Phosphate $\left(\mathrm{KH}_{2} \mathrm{PO}_{4}\right)$ & 175 & - & 0.144 \\
\hline Dipotassium Phosphate $\left(\mathrm{K}_{2} \mathrm{HPO}_{4}\right)$ & 100 & 31 & 0.288 \\
\hline Magnesium sulfate Heptahydrate $\left(\mathrm{MgSO}_{4} \cdot 7 \mathrm{H}_{2} \mathrm{O}\right)$ & 75 & 73.8 & 0.100 \\
\hline Calcium Chloride Dihydrate $\left(\mathrm{CaCl}_{2} \cdot 2 \mathrm{H}_{2} \mathrm{O}\right)$ & 25 & 36 & 0.50 \\
\hline Sodium Chloride Dihydrate ( $\mathrm{NaCl})$ & 25 & - & - \\
\hline Potassium Hydroxide (KOH) & 31 & - & - \\
\hline Iron(II) Sulfate Heptahydrate $\left(\mathrm{FeSO}_{4} \cdot 7 \mathrm{H}_{2} \mathrm{O}\right)$ & 4.98 & - & 0.005 \\
\hline Boric acid $\left(\mathrm{H}_{3} \mathrm{BO}_{3}\right)$ & 11.42 & - & 0.011 \\
\hline Zinc Sulfate Heptahydrate $\left(\mathrm{ZnSO}_{4} \cdot 7 \mathrm{H}_{2} \mathrm{O}\right)$ & 8.82 & - & 0.022 \\
\hline Manganese (II) Chloride Heptahydrate $\left(\mathrm{MnCl}_{2} \cdot 7 \mathrm{H}_{2} \mathrm{O}\right)$ & 1.44 & - & 0.005 \\
\hline Molybdenum Trioxide $\left(\mathrm{MoO}_{3}\right)$ & 0.71 & - & 0.0011 \\
\hline Copper(II) Sulfate Pentahydrate & 1.57 & - & 0.0016 \\
\hline Cobalt (ii) Nitrate or Chloride Hexahydrate & 0.49 & - & 0.0016 \\
\hline Disodium Salt Dihydrate & 50 & 10 & 0.050 \\
\hline Sodium Carbonate & - & 20 & - \\
\hline Citric acid & - & 6 & - \\
\hline Ferric Ammonium Citrate & - & 6 & - \\
\hline Tris base (Tris(hydroxymethyl)-aminomethane) & - & - & 2.42 \\
\hline Ammonium Chloride & - & - & 0.375 \\
\hline
\end{tabular}

\section{Biomass Cultivation and Harvesting}

Mass cultivation of cultures was done by the flask containing $350 \mathrm{ml}$ of autoclaved media (BBM, BG-11and TAP) under sterile conditions. Approximately $3 \%$ of the inoculum from the mother cultures was inoculated and were incubated at room temperature, 16/8 h light: dark photoperiod under fluorescent white light for about 20-25 days. The mass cultivated cultures were harvested at stationary phase (after nearly 20 days) by using REMl High Speed Cooling Centrifuge at 8000 rpm for 10 minutes. This harvested biomass was washed two times with distilled water and the wet biomass was measured and the water content of the biomass was dried by keeping them in hot air oven at $50^{\circ} \mathrm{C}$ and dry weight was measured. Biomass content was calculated from microalgal dry weight produced per liter $(\mathrm{g} / \mathrm{L})$. The powdered biomass was stored at $4^{\circ} \mathrm{C}$ for further lipid extraction and estimation processes.

Biomass yield of harvested microalgae was calculated as following:

Final weight (mg) - Initial weight (mg)

Biomass yield $(\mathrm{mg} / \mathrm{mL})=\frac{\text { Sample Taken }(\mathrm{mL})}{\text { Extraction of Lipids }}$

Extraction of total lipid from the harvested powder dried algal biomass was done by the most common method. $3.75 \mathrm{ml}$ of Chloroform: Methanol (1:2 v/v) was added to each $100 \mathrm{mg}$ of dried, powdered biomass. The samples were then vortexed and kept in a shaker for about $15-20$ minutes. $1.25 \mathrm{~mL}$ of chloroform was added to the samples and strongly vortexed, which was followed by the addition of $1.25 \mathrm{ml}$ of distilled water, and vortexed again. The samples were centrifuged for 10 minutes at $6000 \mathrm{rpm}$ to give two-phase system. The lower layer containing lipid was transferred to round-bottomed flasks, the solvent was removed using a vacuum evaporator or the solvent can be dried off by keeping in hot air oven at $50^{\circ} \mathrm{C}$ until all the solvent completely gets dried. Lipid content of various microalgal strains in different media was calculated as follows:

Lipid Content (\% Dry weight) $=\frac{\text { Mass of the extracted lipid }(\mathrm{mg})}{\text { Mass of the dried biomass }(\mathrm{mg})} \times 100$

\section{Detection of Lipids}

Qualitative and quantitative analysis of the lipids produced is necessary for identification of best lipid producing algae for further efficient biodiesel production. A simple and rapid method of Nile Red staining was used to detect the presence of both neutral and polar lipids in algae.

\section{Nile red Staining}

$5 \mathrm{ml}$ of microalgae culture was taken in a tube and it was centrifuged at 10,000 rpm for 10 min and washed with distilled water 2-3 times. Collect the cell pellets obtained was pre-treated with an ultrasonic precursor or $295 \mu \mathrm{L}$ of $25 \%$ DMSO solution. Furthermore, $15 \mu \mathrm{L}$ of Nile red (9-diethylamino- $5 \mathrm{H}$-benzo [a] phnenoxaphenoxazine-5one) solution (0.5 mg mL-1 in acetone) was added to the suspension and gently vortexed for $1 \mathrm{~min}$. The preparation was incubated for 15 min in dark, the stained microalgae cells were observed under fluorescent microscope (Cellomics Arrayscan Vti HCS Reader) to detect the presence of lipids. The excitation and emission wavelength for the fluorescence determination were selected as $530 \mathrm{~nm}$ and $568 \mathrm{~nm}$ respectively.

\section{Thin layer Chromatography}

Qualitative analysis was performed using Thin Layer Chromatography [13] to determine the relative abundance of TAG's and fatty acids. The extracted lipids were dried overnight and were dissolved in $45 \mu$ of chloroform: methanol (1:2). $45 \mathrm{ml}$ of the solvent system [Petroleum ether: Diethyl ether: glacial acetic acid (70:30:1)] was used. Pour this solvent into the TLC chamber, cover and let the chamber saturate before loading the plates. TLC sheet of $7 \mathrm{~cm}$ height and $4 \mathrm{~cm}$ width was used and mark the plates with a sharp pencil. $2 \mu$ lof the sample and the standard (Coconut oil) were spotted onto the TLC plate carefully. Make sure the spot remains smaller than $4 \mathrm{~mm}$ in diameter. After the spots have dried, repeat loading each standard and sample until you have loaded approximately $10 \mu \mathrm{l}$ each. Let the spots dry and put into the glass chamber containing solvent system. Make sure that the loading area is above the solvent. Immediately lid was closed and the plate was left in the chamber till the solvent reached three quarters of the 
sheet. Then the plate was transferred into the developing chamber containing iodine crystals for development and comparison of the bands.

\section{Direct Transesterification}

The direct transesterification experiment was started with $n$-Hexane, petroleum ether, acetone, diethyl ether, benzene, chloroform and n-butanol, to determine the best co-solvent with methanol for extracting lipids. Mixing methanol, co-solvent and sulphuric acid with dry microalgae powders in a round-bottomed flask (25 ml), this was connected with condensate return equipment. To avoid variation in the stirring power per unit quality, the dosage of microalgae powders was maintained constant $(0.3 \mathrm{~g})$. The ratio of co-solvent to methanol was between 1:3 and 3:1. Temperature and reaction time were varied from $60^{\circ} \mathrm{C}$ to $100^{\circ} \mathrm{C}$ and $1 \mathrm{~h}$ to $3 \mathrm{~h}$, respectively. The mixing solvent dosage $(3-7 \mathrm{ml})$ and catalyst volume $(0.2-1.0 \mathrm{ml})$ were also investigated in the study. After the reaction was completed, the mixture was cooled for $10 \mathrm{~min}$. Then, a saturated sodium chloride solution and n-hexane were added and the mixture was centrifuged to achieve phase separation. The volume yield can be calculated by

Volume yield $(\%)=($ Volume of product $/$ Volume of oil fed $) \times 100$

\section{Results and Discussion}

The aim of this present study is to examine the microalgae species from Western Ghats region and comparing the composition of the media which would be suitable for the growth of microalgal strain with a short lag phase. Totally 15 samples were collected from different location of Western Ghats regions such as Nilgiris (Tamilnadu), Dharmasthala (Karnataka) and Halowar (Goa). Among 15 samples, algal growth was occurred in 10 samples (6 soil and 4 water samples) and it has named according to the samples collected from different locations were shown in [Fig-1] Based on cell morphology and colonial characteristics microscopic identification of th]e isolates were specified by American Public Health Association (APHA, 1985) and were tentatively confirmed as the respective strains under 40X [Fig-2]. The PCR amplified products of all the strains were identified by 18S rRNA sequencing which shows $99.9 \%$ similarity to the corresponding organisms and FASTA gene sequences were deposited in the GenBank database under the accession number.
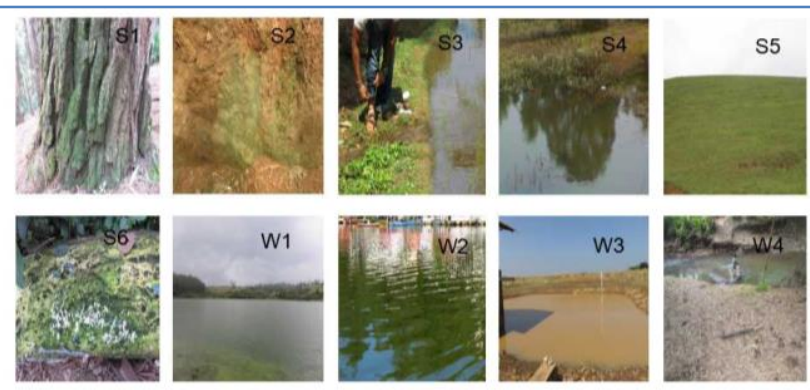

Fig-1 Location of samples collected from different regions

S1-Pine forest (Ooty), S2-Gymkhana golf course (Ooty), S3- Belgeha (Dharmasthala), S4-Ponda (Goa), S5-Ninth mile shooting spot (Ooty), S6-Teak wood (Ooty), W1- Kamraj Dam (Ooty), W2-Ooty city lake, W3- Mudumalai Tank Forest, W4-Kallabutty.
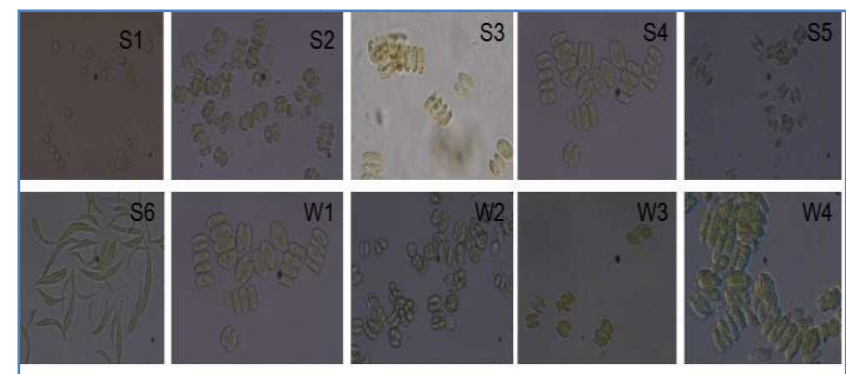

ated microalgal strains

Fig-2 Microscopic Identification of isolated microalgal strains
S1-Desmodesmus abundans sp. S2- Scenedesmus pectinatus sp. S3-
Tetranephris brasiliensis sp. S4-Desmodesmus armatus sp. S5-Scenedesmus costato-granulatus sp. S6-Neocystis brevis W1-Chlorella Sorokiniana sp. W2Scenedesmus acutus sp. W3-Pseudomuriella sp W4-Chlorella minutissima sp.

The growth condition of all the above selected strains were studied in three different medium (BBM, BG-11 and TAP) and the micronutrients necessary for the stimulation of the growth in the media are tabulated. Like other microorganisms, microalgae growth can undergo four growth phases: lag, exponential, stationary, and lysis [13]. The microalgal growth curves obtained in this research illustrate all four characteristic growth phases in a batch culture of microalgae. But in the case of commercial media (BBM, BG-11 and TAP) the decline phase (also called lysis phase) was not evident due to short cultivation time and it takes long time to reach the decay phase. The observations of growth rate were measured on every alternative days at $600 \mathrm{~nm}$. In BBM media, highest growth was occurred in Neocystis brevis (1.685), Scenedesmus pectinatus sp. (1.632) and Chlorella minutissima sp (1.595) on $29^{\text {th }}$ day of cultivation as shown in [Fig-3]. The lowest growth rate was occurred in Tetranephris brasiliensis sp. (0.754) grown in BBM media. Scenedesmus costato-granulatus sp. (1.77) and Neocystis brevis (1.754) showed maximum growth rate whereas Desmodesmus abundans sp. $(0.816)$ showed minimum growth when cultivated in BG-11 media as shown in [Fig-4]. The growth curves of microalgae in BBM and BG-11 media clearly depicts that the cultures were still in exponential phase when cultured for 30 days. In TAP media, all the microalgal strains showed maximum growth with the O.D. values reaching more than 3.0. Desmodesmus abundans sp. showed highest growth rate of 3.161 on $17^{\text {th }}$ day of cultivation whereas Neocystis brevis strain showed the lowest growth rate of 1.516. The time required to reach stationary phase varied for different strains when cultivated in TAP media as shown in [Fig-5]. In all the strains the growth rate was decreased after 17-19th day in TAP medium. Cell biochemical evidences show that microalgae can effectively use $\mathrm{NO}^{3-}, \mathrm{NO}^{2-}, \mathrm{N}^{2}$ or $\mathrm{NH}^{4+}$ as nitrogen sources, but via absolutely different pathways, since only the most reduced form is used to synthesize biomolecules [14]. The results of these experiments showed that the growth rates of wild-type and mutant cultures of $C$. rein hartdii were higher in the presence of acetate when compared to cultures grown in the absence of acetate [15].

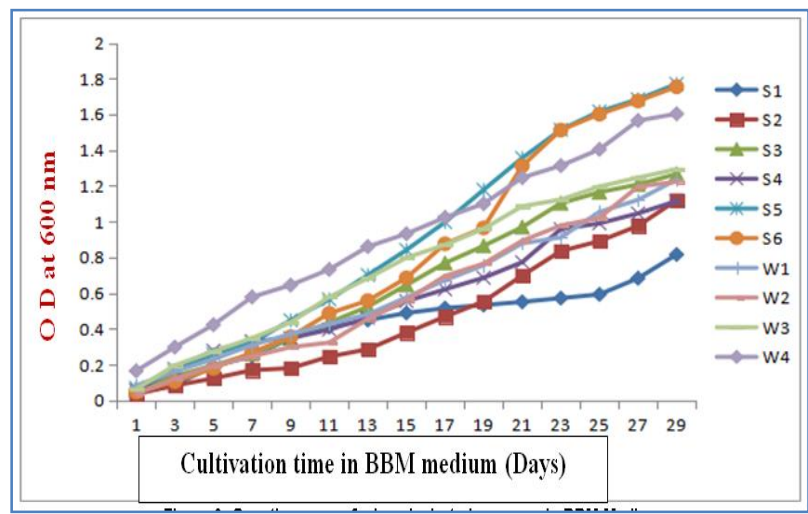

Fig-3 Growth curves of microalgal strains grown in BBM Media

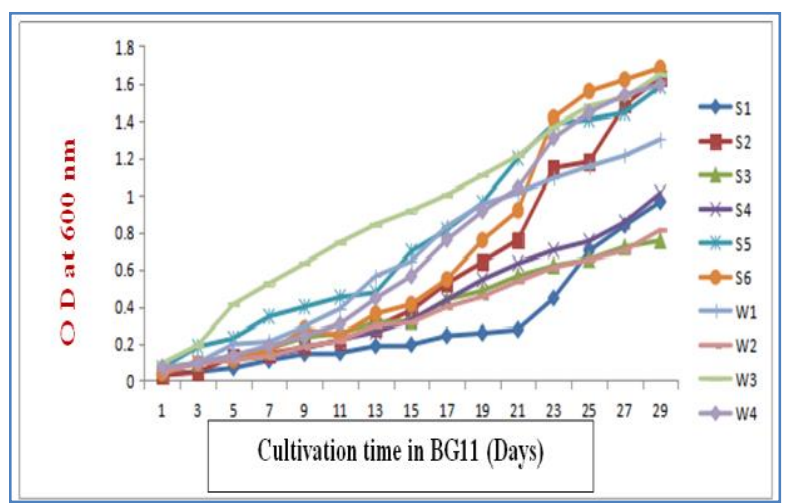

Fig-4 Growth curves of microalgal strains grown in BG11 Media 


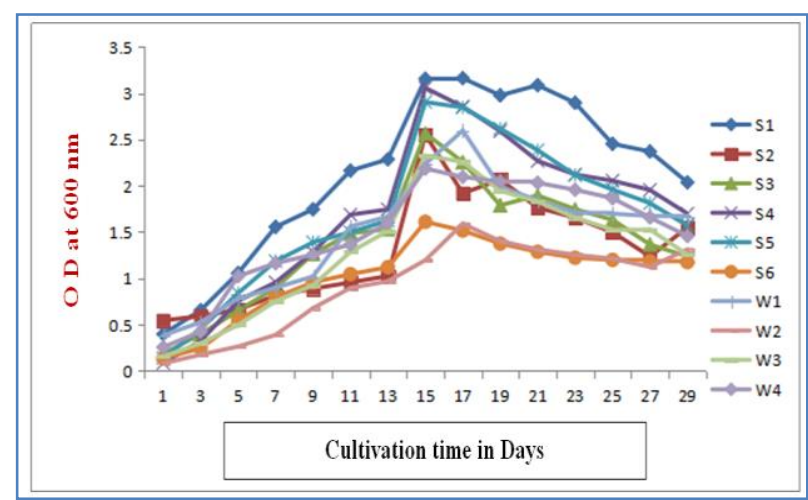

Fig-5 Growth curves of microalgal strains grown in TAP Media

Mass cultivation of all the pure cultures in BG11, BBM and TAP media was shown in Plate 3. Microalgae can grow profusely under suitable conditions and with sufficient nutrients. They often double their biomass within $3.5 \mathrm{~h}$ or, at the longest, $24 \mathrm{~h}$ during their exponential growth phase [4]. The net wet and dry biomass differed among the examined microalgal species as shown in [Fig-6-7]. Algal growth is directly affected by the availability of nutrients and light, the $\mathrm{pH}$ stability, temperature, and the initial inoculum density. Under similar environmental conditions, average specific wet and dry biomasses were found maximum in TAP medium in comparison to BBM and BG-11. Chlorella minutissima sp., Desmodesmus abundans sp., and Scenedesmus costato-granulatus sp. yielded highest dry biomass of $0.312 \mathrm{mg} / \mathrm{mL}, 0.308 \mathrm{mg} / \mathrm{mL}$, and $0.285 \mathrm{mg} / \mathrm{mL}$ in TAP media.

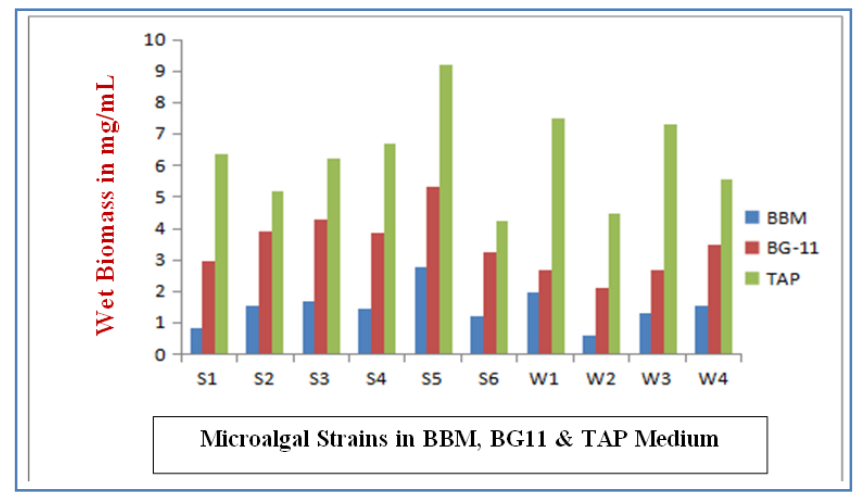

Fig- 6 Comparison of Wet algal Biomass yield obtained from BBM, BG11 and TAP Medium.

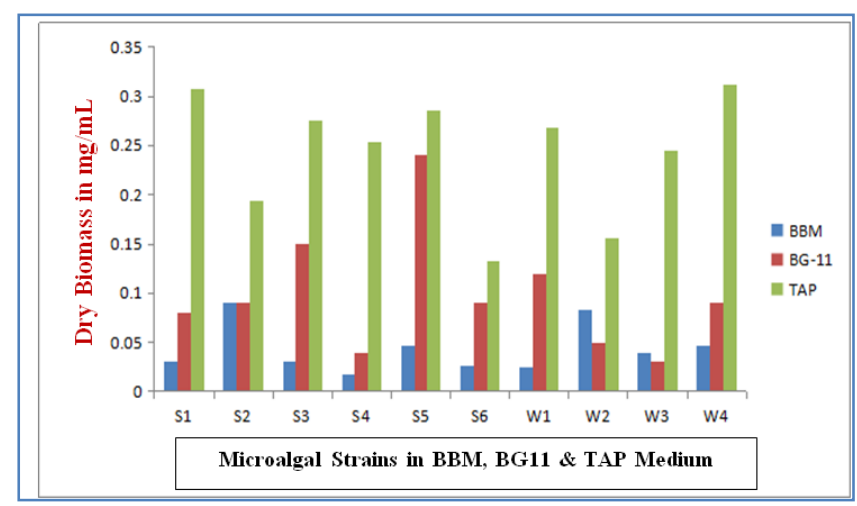

Fig-7 Comparison of Dry algal Biomass yield obtained from BBM, BG11 and TAP Medium

Oil content in microalgae can exceed $80 \%$ by weight of dry biomass [15]. Oil levels of $20-50 \%$ are quite common. So far the higher amount was been reported in Botryococcus braunii (25-75\%), Schizochytrium sp. (50-77\%), Nannochloropsis sp. $(31-68 \%)$ and chlorella sp. (28-32\%). Oil productivity, that is the mass of oil produced per unit volume of the microalgal broth per day, depends on the algal growth rate and the oil content of the biomass. Microalgae with high oil productivities are desired for producing biodiesel. Extraction methods used should be fast, effective and non-damaging to lipids extracted and easily scaled up. Depending on the specific algae species and their cultivation conditions, however, microalgal lipid production may range widely from 2 to $75 \%$ [2]. In some extreme cases, it can reach $70 \%-90 \%$ of dry weight [4]. In the present study, maximum lipid content of $43.7 \%, 42.6 \%$ was obtained in Desmodesmus abundans sp. and Desmodesmus armatus sp whereas the lowest lipid content of $17.5 \%$ was observed in Scenedesmus acutus sp. extracted in TAP media. Similarly, $42.6 \%$, $40.6 \%$ and $42.5 \%$ showed highest lipid content in BBM and BG11 media [Fig-8]. Nitrogen source is one of the major factors which affect lipid accumulation in microalgae. Since atmospheric $\mathrm{CO}_{2}$ accumulation has a serious effect on the global environment, the control of total $\mathrm{CO}_{2}$ emission into the atmosphere is considered to be an important issue related to the biosphere. Liquefaction using various model substrates revealed that a high liquefaction yield was obtained from cell components containing hydrophobic compounds such as lipids, fatty acids and fatty acid esters. Among marine microalgae species, cells of the genus Nannochloris are known to contain a large amount of intracellular lipids due to nitrate depletion during cultivation.

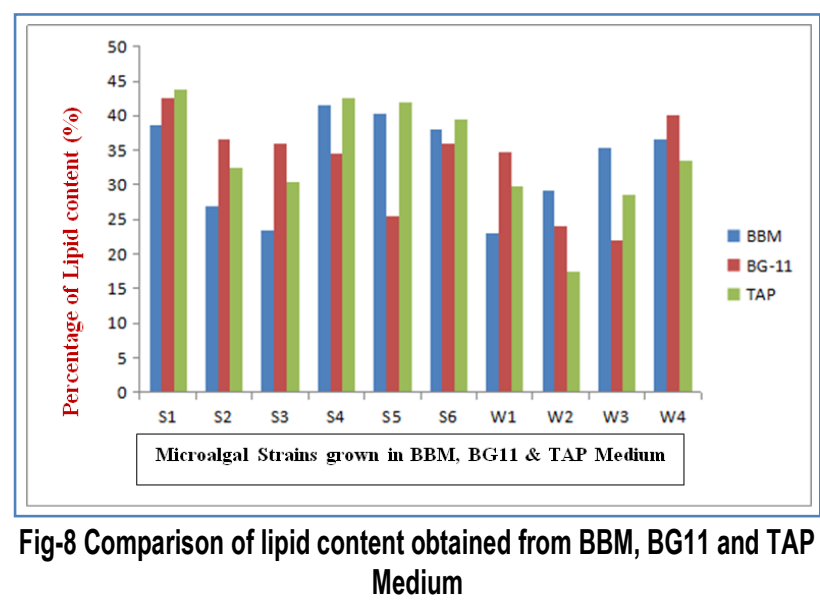

The relative ratio of TAG/ FFA/polar lipids varied by algae species, even for the same species, the compositions of fatty acids and complex lipids in algae heavily fluctuate depending on growth conditions such as light, temperature, nitrogen level, salt stress and the growth stages at which they are harvested. [Fig-9] showed the intense red colour fluorescent which confirms the accumulation of total lipids in microalgae species. In several reports reported the same results by polar lipids (i.e., phospholipids) which are mostly present in membranes, are stained in red whereas neutral lipids (esterified cholesterol and triglycerides) which are present in lipid droplets are stained in yellow [16]. Various factors including algal species and measurement conditions may affect the penetration of Nile red into the cells and binding to lipid bodies causing irreproducible results [17].
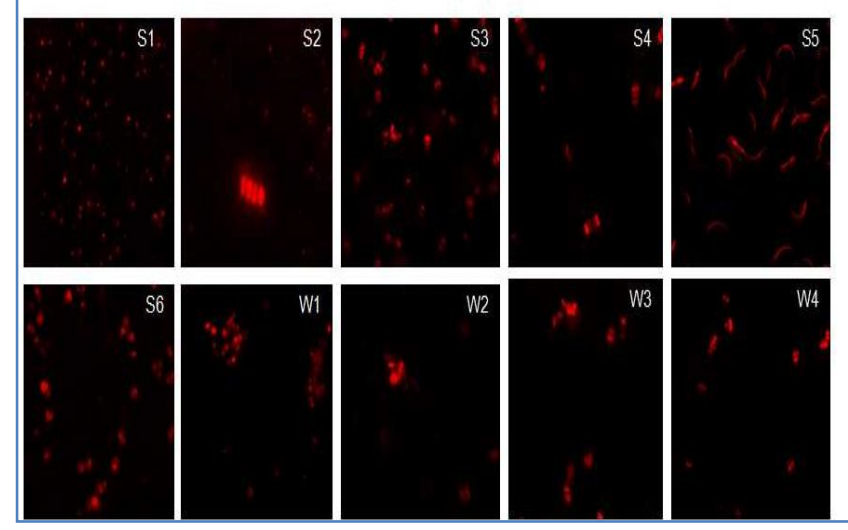

Fig-9 Nile red staining of isolated microalgal strains shows the intense red colour fluorescent which confirms the accumulation of total lipids 
After optimizing concentration of the standards, the lipids extracted using the Bligh Dyer method was run on TLC. Clear band separation was observed. Bands corresponding to free fatty acids and TAG's were observed by using coconut oil (properly diluted in methanol) as standards respectively. It showed the presence of large quantity of free fatty acid and little amount of triacylglycerol (TAG). This shows that the lipid content of the microalgal cultures is good [Fig-10]. Tentative identification of the lipid classes was performed by using standards that were spotted next to samples. The fatty acids obtained was analyzed using the standard as coconut oil where Palmitic acid (C16) and oleic monosaturated (C18:1) fatty acids has been obtained in all the samples.

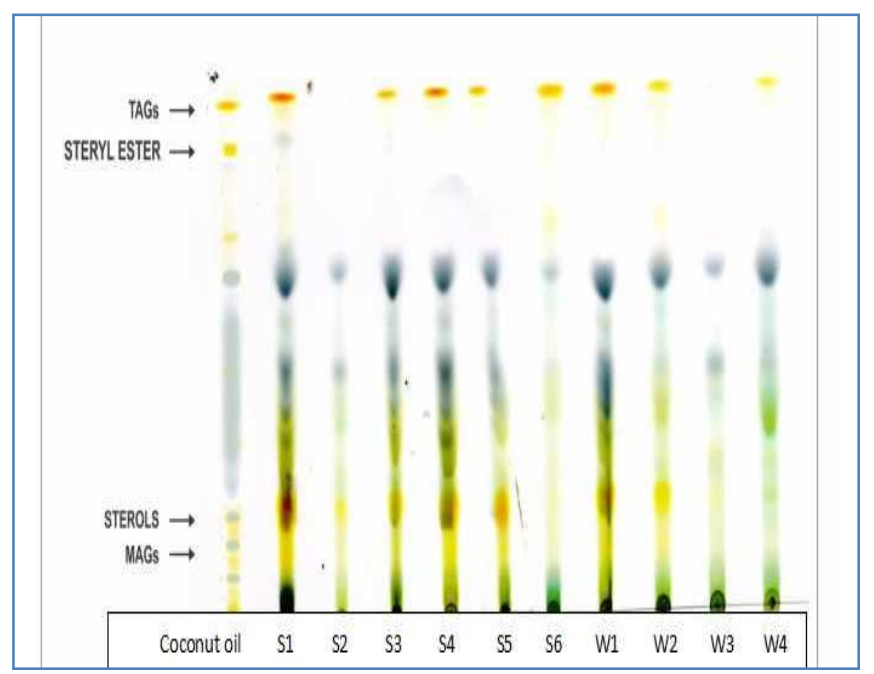

Fig-10 shows lipid profiling of microalgal strains in TLC Plate

\section{Direct-Transesterification}

In the direct transesterification study, dried microalgae biomass was not pretreated by any other method to destroy the cell wall. Among the different cosolvents tried in the experiment $n$-hexane showed a higher efficiency among the chosen solvent [Fig-11]. The reason for these results is that $n$-hexane is a nonpolar solvent, which not only were capable of dissolving long-chain triglycerides, resulting in homogeneous catalysis. [Table-2] shows the reaction condition with that of $n$-hexane to methanol ratio $1: 2$, solvent dosage $5.0 \mathrm{ml}$, reaction temperature $90^{\circ} \mathrm{C}$, reaction time $2.0 \mathrm{~h}$ and catalyst volume $0.5 \mathrm{ml}$, the conversion yield of the direct transesterification can reach $90.23,89.25$ and 86.65 for Desmodesmus abundans, Desmodesmus armatus and Scendesmus costatogranulatus respectively which produced high lipid content in TAP media. Other reports showed the same conversion yield of $90.02 \pm 0.55 \mathrm{wt} . \%$ with the reaction condition that $n$-hexane to $75 \%$ ethanol ratio $1: 2$, solvent dosage $6.0 \mathrm{ml}$, reaction temperature $90^{\circ} \mathrm{C}$, reaction time $2.0 \mathrm{~h}$ and catalyst volume $0.6 \mathrm{ml}$ [13].

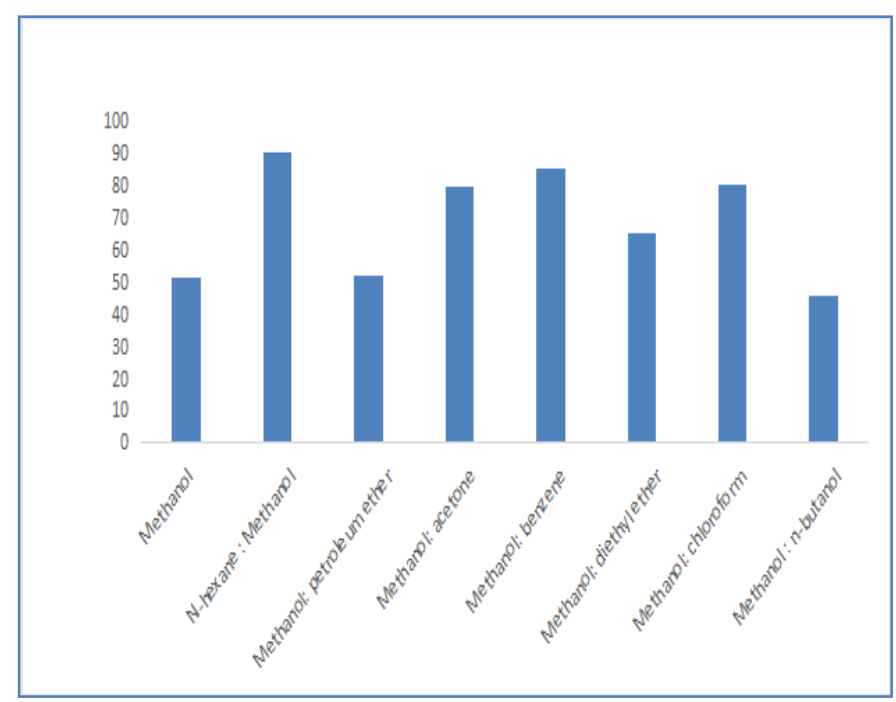

Fig-11 shows Conversion yield of methyl esters efficiency among the chosen solvent.

\begin{tabular}{|c|c|c|c|c|c|c|c|c|}
\hline \multirow[b]{2}{*}{ Varying Parameter } & \multirow[b]{2}{*}{$\begin{array}{l}\text { N-hexane : } \\
\text { Methanol }\end{array}$} & \multirow[b]{2}{*}{$\begin{array}{c}\text { Solvent } \\
\text { dosage (ml) }\end{array}$} & \multirow[b]{2}{*}{$\begin{array}{l}\text { Temperature } \\
\left({ }^{\circ} \mathrm{C}\right)\end{array}$} & \multirow[b]{2}{*}{$\begin{array}{l}\text { Reaction time } \\
\text { (hr) }\end{array}$} & \multirow[b]{2}{*}{$\begin{array}{c}\text { Catalyst } \\
\text { volume (ml) }\end{array}$} & \multicolumn{3}{|c|}{ Conversion yield } \\
\hline & & & & & & $\begin{array}{l}\text { Desmodesmus } \\
\text { abundans }\end{array}$ & $\begin{array}{l}\text { Desmodesmus } \\
\text { aramatus }\end{array}$ & $\begin{array}{l}\text { Scendesmus costato } \\
\text { granulatus sp }\end{array}$ \\
\hline \multirow{5}{*}{ N-hexane : Methanol } & $1: 3$ & 5.0 & 90 & 2.0 & 0.5 & 82.65 & 70.15 & 72.36 \\
\hline & $1: 2$ & 5.0 & 90 & 2.0 & 0.5 & 89.24 & 81.55 & 82.86 \\
\hline & 1:1 & 5.0 & 90 & 2.0 & 0.5 & 62.75 & 76.25 & 79.65 \\
\hline & $2: 1$ & 5.0 & 90 & 2.0 & 0.5 & 56.82 & 70.45 & 68.32 \\
\hline & $3: 1$ & 5.0 & 90 & 2.0 & 0.5 & 30.35 & 59.25 & 53.65 \\
\hline \multirow{5}{*}{ Solvent dosage } & $1: 2$ & 3.0 & 90 & 2.0 & 0.5 & 70.50 & 70.28 & 68.32 \\
\hline & $1: 2$ & 4.0 & 90 & 2.0 & 0.5 & 86.95 & 78.62 & 74.68 \\
\hline & $1: 2$ & 5.0 & 90 & 2.0 & 0.5 & 88.22 & 82.66 & 83.65 \\
\hline & $1: 2$ & 6.0 & 90 & 2.0 & 0.5 & 80.75 & 81.89 & 84.36 \\
\hline & $1: 2$ & 7.0 & 90 & 2.0 & 0.5 & 60.51 & 68.56 & 76.25 \\
\hline \multirow{5}{*}{ Temperature } & $1: 2$ & 5.0 & 60 & 2.0 & 0.5 & 68.35 & 70.36 & 65.36 \\
\hline & $1: 2$ & 5.0 & 70 & 2.0 & 0.5 & 79.86 & 76.34 & 80.65 \\
\hline & $1: 2$ & 5.0 & 80 & 2.0 & 0.5 & 83.25 & 84.65 & 82.36 \\
\hline & $1: 2$ & 5.0 & 90 & 2.0 & 0.5 & 89.50 & 86.32 & 79.36 \\
\hline & $1: 2$ & 5.0 & 100 & 2.0 & 0.5 & 82.76 & 80.36 & 68.80 \\
\hline \multirow{5}{*}{ Reaction time } & $1: 2$ & 5.0 & 90 & 1.0 & 0.5 & 68.75 & 66.25 & 70.56 \\
\hline & $1: 2$ & 5.0 & 90 & 1.5 & 0.5 & 82.65 & 80.65 & 77.89 \\
\hline & $1: 2$ & 5.0 & 90 & 2.0 & 0.5 & 90.23 & 89.25 & 86.65 \\
\hline & $1: 2$ & 5.0 & 90 & 2.5 & 0.5 & 83.45 & 81.65 & 85.20 \\
\hline & $1: 2$ & 5.0 & 90 & 3.0 & 0.5 & 78.65 & 70.95 & 79.23 \\
\hline \multirow{5}{*}{ Catalyst volume } & $1: 2$ & 5.0 & 90 & 2.0 & 0.2 & 81.90 & 79.35 & 80.66 \\
\hline & $1: 2$ & 5.0 & 90 & 2.0 & 0.4 & 83.61 & 81.55 & 82.36 \\
\hline & 1:2 & 5.0 & 90 & 2.0 & 0.6 & 88.55 & 86.25 & 83.25 \\
\hline & $1: 2$ & 5.0 & 90 & 2.0 & 0.8 & 69.33 & 72.55 & 79.21 \\
\hline & $1: 2$ & 5.0 & 90 & 2.0 & 1.0 & 40.85 & 52.85 & 63.56 \\
\hline
\end{tabular}

\section{Conclusion}

All the 10 samples were dominant microalgal species among the specific regions and microalgal strains grown better and faster in TAP media. The effect of ammonium salts clearly depicts the fast growth and high lipid content under similar environmental conditions, average specific wet and dry biomass were found maximum in TAP medium in comparison to $\mathrm{NaNO}_{3}$ in BBM and BG-11. Direct transesterification process of Desmodesmus abundans, Desmodesmus armatus and Scendesmus costato-granulatus yielded high conversion rate which clearly 
indicates that it can be used as potential species for biodiesel production. But the key bottleneck of biodiesel production from microalgae is that the current technologies do not allow an economic and sustainable biofuel production at today's energy prices, although high biomass and lipid productivity make them promising as a feedstock for renewable energy. Moreover, efforts should be made by focusing research on development of large-scale cost-effective cultivation systems.

Application of research: There is a prospective in algal biotechnology by exploitation of different media composition for the growth formulation in microalgae species which is inexpensive for biomass cultivation in large scale production of lipids that can be harnessed for biodiesel production.

Research Category: Biodiesel production from Microalgae

\author{
Abbreviations: \\ BBM - Bold Basal Media \\ BG11 - Blue Green 11 media \\ TAP - Tris-Acetate Phosphate media
}

Acknowledgement / Funding: Author thankful to University of Agricultural Sciences, GKVK Campus, Bangalore, 560065, Karnataka. Author thankful to DRDO-LSRB, Government of India for the financial support

\section{Research Guide or Chairperson of research: Dr K. M. Harini Kumar}

University: University of Agricultural Sciences, GKVK Campus, Bangalore, 560065, Karnataka

Research project name or number: PhD Thesis

Author Contributions: All author equally contributed

Author statement: All authors read, reviewed, agree and approved the final manuscript

\section{Conflict of Interest: None declared}

Ethical approval: This article does not contain any studies with human participants or animals performed by any of the authors.

\section{References}

[1] Parveen Kumar, Pradeep Kumar Sharma, Pradip Kumar Sharma and Deepansh Sharma (2015) JIPBS, 2(2), 135-143.

[2] Mata T.M., Martins A.A. and Caetano N.S. (2010) Renew Sust Energ Rev, $14,217-232$

[3] Chisti Y. (2006) Environ Eng Manage J., 5 (3), 261-274.

[4] Chisti Y. (2007) Biotecnol Adv., 25, 294-306.

[5] Hu G., Sommerfeld M., Jarvis E., Ghirardi M., Posewitz M. and Seibert M. (2008) Plant j., 54, 621-639.

[6] Demirbas A. and Demirbas M.F. (2011) Energy Convers Manag, 52,163170.

[7] Chisti Y. (2008) Trends Biotechnol., 26, 126-131.

[8] Chen Y.F. (2011) Production of biodiesel from algal biomass: current perspectives and future. Academic Press, Waltham, p. 399.

[9] Parker M.S., Mock T. and Armbrust E.V. (2008) Annu Rev Genet., 42, 619645.

[10] Cuellar Bermudez S. P., Aguilar Hernandez I., Cardenas Chavez D. L., Ornelas Soto N., Romeroogawa M.A. and Parra Saldivar R. (2014) Microb Biotechnol., 8,190-209.

[11] Chisti Y. (2013) J Biotechnol.,167, 201-214.

[12] Hannon M., Gimpel J., Tran M., Rasala B. and Mayfield S. (2010) Biofuels 1, 763-784.

[13] Feng L., Yeung W., Xu Y.H., Wang S.S., Zhu Q. and Xiang P. (2011) Asian Pac J Cancer Prev., 12 (2), 403-8.
[14] Yan Zhang, Ya Li. and Xu Zhang (2015) Bioresource Technology, 19(6), 712-715.

[15] Glass J. B., Wolfe Simon F. and Anbar A. D. (2009) Geobiology, 7, 100123.

[16] Therien J. B., Zadvornyy O. A., Posewitz M. C., Bryant D. A. and Peters J. W. (2014) Biotechnology for Biofuels, 7(1), 154.

[17] Diaz G., Melis M., Batetta B., Angius F. and Falchi A. M. (2008) Micron., 39 (7), 819-824.

[18] Chen W., Zhang C., Song L., Sommerfeld M. and Hu Q. (2009) Journal of Microbiological Methods, 77 (1), 41-47. 